University of Nebraska - Lincoln

DigitalCommons@University of Nebraska - Lincoln

2009

\title{
Team Level Positivity: Investigating Positive Psychological Capacities and Team Level Outcomes
}

\author{
Bradley J. West \\ University of Nebraska - Lincoln, bwest4@unl.edu \\ Jaime L. Patera \\ University of Nebraska - Lincoln \\ Melissa K. Carsten \\ University of Nebraska - Lincoln
}

Follow this and additional works at: https://digitalcommons.unl.edu/managementfacpub

Part of the Management Sciences and Quantitative Methods Commons

West, Bradley J.; Patera, Jaime L.; and Carsten, Melissa K., "Team Level Positivity: Investigating Positive Psychological Capacities and Team Level Outcomes" (2009). Management Department Faculty Publications. 21.

https://digitalcommons.unl.edu/managementfacpub/21

This Article is brought to you for free and open access by the Management Department at DigitalCommons@University of Nebraska - Lincoln. It has been accepted for inclusion in Management Department Faculty Publications by an authorized administrator of DigitalCommons@University of Nebraska - Lincoln. 


\title{
Team Level Positivity: Investigating Positive Psychological Capacities and Team Level Outcomes
}

\author{
Bradley J. West, Jaime L. Patera, and Melissa K. Carsten \\ Department of Management, Gallup Leadership Institute, \\ University of Nebraska-Lincoln, Lincoln, Nebraska, U.S.A. \\ Corresponding author - B. J. West, 8250 Rockledge Rd., Lincoln, NE 68506, U.S.A.; \\ email westbrad@gmail.com
}

\begin{abstract}
The movement toward positive psychology has uncovered the important role that positivity plays in both individual and organizational success. Given that work teams are becoming increasingly embedded in organizational structures, it is surprising that few researchers have investigated positivity at the team level. The present study examines the emergence of team level positive psychological capacities and their relationship with team outcomes (e.g., cohesion, cooperation, coordination, and conflict and team satisfaction) during two team sessions. Results from 101 teams suggest that team optimism is an important predictor of team outcomes when teams are newly formed, whereas team resilience and team efficacy show greater explanatory power after several team interactions. Implications of the findings are discussed, as well as possible avenues for additional research.
\end{abstract}

\section{Introduction}

Teams have become a centerpiece of organizational structure with team-based collaboration becoming progressively more important to organizational performance. In a recent poll conducted by the Center for Creative Leadership, an overwhelming 83 per cent of respondents identified teams as a key ingredient to organizational success (Center for Creative Leadership, 2006). As organizations and researchers alike have been increasingly focused on the performance of both teams and individuals within teams (e.g., Gully, Incalcaterra, Joshi, \& Bxeauien, 2002; Guzzo \& Shea, 1992; Ilgen, Major, Hollenbeck, \& Sego, 1993), attention has been directed toward identifying the specific characteristics and internal processes that elicit team effectiveness. Surprisingly, given the recent surge in positive psychology and the increased volume of research being conducted on the combination of individual traits, attitudes, and characteristics that make up a team's composition, relatively little work has focused on the impact of positive psychology in a team context.

The positive psychology movement urges psychologists to "adopt a more appreciative perspective regarding human potential, motives and capacities" with an interest in finding out "what works, 
what is right, and what is improving" (Sheldon \& King, 2001, p. 216). Specific to the organizational context, positive organizational behavior (POB) is defined as "the study and application of positively oriented human resource strengths and psychological capacities that can be measured, developed, and effectively managed for performance improvement in today's workplace" (Luthans, 2002b, p. 59). Initial strides for theoretical development and empirical tests of positive psychological capacities have primarily been conducted at the individual level given that individuals provide the most tangible context from which to initially examine personal strengths. However, as individuals are embedded in social relations among groups, teams, and organizations (Day, 2000), it follows intuitively that individuals within a team may also be influenced in important ways by some manifestation of individual strengths or capacities.

As researchers strive to understand individual employees from a positive psychological perspective, it becomes pertinent to consider individuals' experiences within the proximal contexts that teams provide. However, despite the increased application of organizational positivity and the movement toward identifying positive characteristics, attributes, and behaviors of individuals (Cameron, Dutton, \& Quinn, 2003; Luthans, 2002b; Seligman \& Csikszentmihalyi, 2000), the potential impact of such variables in a team context has yet to be examined. The present study addresses this gap by investigating the emergence of team level positive psychological capacities and their relationship with team outcomes (e.g., cohesion, cooperation, coordination, and conflict and team satisfaction). Specifically, we focus on team level representations of the positive psychological capacities that have met the POB inclusion criteria (e.g., efficacy, optimism, resilience; Luthans, 2002a) and which may have a unique influence on important team level outcomes (e.g., cohesion). Given the numerous calls for an increased appreciation of issues related to team development (e.g., Kozlowski, Gully, Nason, \& Smith, 1999), a longitudinal design was employed to determine if the potential influence of team level positivity was dependent on the amount of interaction among team members.

\section{Positive psychology and team level outcomes}

Similar to individuals acting alone, individuals performing as teams tend to display somewhat regular patterns of behavior and processes that are evident to both other team members and observers (Stewart, 2003). Providing a possible explanation for such behavior, Terrion and Ashforth (2002) provide evidence showing that individuals working in team contexts often forego their individual identities to take on the identity of their team. Given that individuals strongly identify with their teams, it is plausible to speculate that a team's positivity may hold the potential to influence teammates and their interactions toward the completion of a task. This is particularly true when work outcomes are team level products that represent an amalgamation of individual efforts.

In line with the call for positive approaches to psychological research (e.g., Compton, 2005; Peterson \& Seligman, 2004) it is important to expand the focus beyond traditional outcomes in team-based research such as individual and team performance. With two of the goals of positive psychology and POB being to utilize the full potential of human resources (Avolio, 2005) and the positive development of employee experiences (Watson, Clark, \& Tellegen, 1988) it becomes critical to understand how positive psychological capacities drive the within-team experience to promote favorable reactions to teamwork and to elicit the synergistic benefits assumed by team-based work structures. Thus, phenomena traditionally treated as process variables such as cohesion, cooperation, coordination, conflict, and team satisfaction were utilized to provide a means of investigating the valence of teammates' experiences within the team. These "process" variables will be referred to generally as "team outcomes" for the purpose of this study. 


\section{Cohesion}

Guzzo and Shea (1992) define cohesiveness as "the forces that bind members to each other and to their group" (p. 284). Cohesion may be thought of as consisting of both the extent to which individuals are cohesive toward the task and toward one another on an interpersonal level (Mullen \& Copper, 1994). However, given that both components are closely tied to the concept of binding team members together, cohesion is often treated as a single construct and was treated as such in this study. Cohesion has generally been shown to relate positively to various outcomes such as team viability (Barrick, Stewart, Neubert, \& Mount, 1998) overall team performance (e.g., Mullen \& Copper, 1994) and team effectiveness (Barrick et al., 1998).

\section{Conflict}

In the team setting, conflict is defined by interpersonal disagreement and divergence that causes rifts or dissatisfaction among team members. Interteam conflict is a somewhat enigmatic team process that has been linked to performance decrements due to interpersonal incompatibility and task disagreements (Kozlowski \& Bell, 2003). In ongoing teams, increased levels of conflict may lead to breakdowns in the interactions between teammates, a failure to attend to the interdependencies required for effective long-term team performance, and intentions to withdraw from the team (Kozlowski \& Bell, 2003).

\section{Coordination and cooperation}

Coordination has been defined as "activities required to manage interdependencies with the team workflow" (Kozlowski \& Bell, 2003, p. 38), whereas cooperation is defined as "the willful contribution of personal efforts to the completion of interdependent jobs" (Wagner, 1995, p. 152). Coordination primarily centers on communication and activities relating to temporal planning whereas cooperation involves communication and activities related to interactive assistance. Coordination and cooperation are regarded as important team processes and have both been linked to team performance (e.g., Stout, Salas, \& Carson, 1994; Wagner, 1995).

\section{Team satisfaction}

Linkages between general job satisfaction and various organizational outcomes such as turnover, organizational citizenship behaviors, as well as with the general health and well being of employees have been supported (Crampton \& Wagner, 1994; O’Driscoll \& Beehr, 1994; Organ \& Ryan, 1995). Given the prevalence of team-based work structures discussed earlier, it stands to reason that employee job satisfaction may in part be a function of how satisfied employees are with the teams that they operate within. Furthermore, research by Jinnett and Alexander (1999), suggests that team satisfaction is significantly related to an individual's intent to leave the organization. Thus, team satisfaction represents a potentially important variable and one which positive team level characteristics are likely to influence.

\section{Team level POB capacities and relationships with team outcomes}

Positive organizational behavior emphasizes the positive human strengths that individuals exhibit in the workplace; placing more emphasis at the microorganizational level with the distinct aspect of malleability or openness to development (Luthans, 2002b). In addition, POB capacities must meet the criterion of being measurable, and applicable to the workplace (Luthans, 2002a). POB constructs may be developed independently by individuals or built into training programs by organizations (Luthans, Avey, \& Patera, 2007). 
Three distinct variables of interest that meet the established POB criterion and have been defined are self-efficacy, resilience, and optimism (Luthans, 2002a; Luthans, Avolio, Avey, \& Norman, 2007). Each of these three constructs is useful in this study at the team level due to their potential relationships with team processes (e.g., cohesion). Similar to constructs operationalized at the team level, such as personality (e.g., Barrick et al., 1998; LePine, Colquitt, \& Erez, 2000), team level positive psychological capacities may be considered as isomorphic representations of individual psychological capacities. In this way, it is plausible to consider both individual and group representations of a single positive psychological capacity (see Kozlowski \& Klein, 2000). Descriptions of these selected positive capacities as well as discussion concerning the possible relationships with team outcome variables are discussed below.

\section{Team efficacy}

At the individual level, self-efficacy, defined as the extent to which individuals "can execute courses of action required to deal with specific situations" (Bandura, 1997, p. 182), has been strongly linked to various positive work related outcomes ranging from basic brainstorming to complex scientific work (see Stajkovic \& Luthans, 1998 for a review). Similarly, team efficacy is a team's shared belief in its collective ability to perform a task (Bandura, 1997) and has been shown to predict team performance across multiple studies (e.g., Campion, Medsker, \& Higgs, 1993; Gibson, 1999; Mitchell, 1997). Efficacious teams are more confident about their task at hand, and are therefore more likely to actively engage in their work and to proactively interact with each other toward successful completion of the task (assuming a sufficient level of task interdependence, Katz-Navon \& Erez, 2005). A team displaying motivated, directed, and effective behavior toward a goal, as well as one which demonstrates adequate amounts of interaction via interpersonal exchanges has a greater likelihood of developing cohesion.

It is likely that team efficacy is also related to a team's experience with higher or lower levels of cooperation and coordination. Teams that hold the collective attitude of "we can do this," that display directive task-based behavior, and view their team as a capable and potentially successful entity are more likely than teams that are low on team efficacy to engage in active planning, delegation of tasks to capable teammates, and alignment of temporal processes.

We also suggest that highly efficacious teams are more likely than others to report higher levels of satisfaction with their team, primarily due to a strong belief in the capability of the team. Given the links established between efficacy and performance (Gully et al., 2002; Stajkovic \& Luthans, 1998), this suggests a potentially strong relationship between the efficacy of the team and the reward/ recognition level received by the team, in turn possibly influencing levels of team satisfaction. In addition, highly efficacious teams that believe in their ability to succeed may also believe in their ability to work through interpersonal disagreements, thus serving to minimize experienced conflict.

\section{Team optimism}

Optimism has been described as an attribution that is measured based on explanatory styles (Seligman \& Schulman, 1986). An optimistic individual achieving success will make global, stable, and internal attributions of their success. Contrarily, when encountered with failure, optimists make specific, unstable, and external attributions. A complementary yet divergent explanation of optimism comes from Carver and Scheier (2003) who define optimists from an expectancy perspective as individuals that simply expect good things to happen to them.

Although not traditionally treated as a team level construct, the qualities of an optimist translate well to a team level positive capacity. From an expectancy theory perspective, a team with shared beliefs and expectations regarding the likelihood of positive outcomes is more likely than a team that lacks such expectations to actively engage in work tasks. Given Seligman and Schulman's (1986) ap- 
proach to optimism, it may also be expected that optimistic teams would adopt an internal attribution toward their success and perceive value in taking control over team outcomes. In terms of coordination, optimistic teams may therefore display more effort toward effectively developing a coordinated plan. Similarly, optimistic teams with an internal locus of control may perceive more value in eliciting the input and assistance of all of the team members, encouraging full engagement among teammates with regard to interactions and communication, thus increasing cooperation.

Conversely, teams that do not hold the belief that positive outcomes are eminent and tend toward external attributions may be more likely to perceive uncontrollable threats in the environment. Such threats may take the form of competition from other teams, anxiety regarding the potential for poor task performance, and even threats from fellow teammates. Individuals in these types of teams may display a tendency to regress toward self-protective behavior (Driskell \& Salas, 1991) and a lack of internal locus of control. As a result, behavior such as careful planning and interactive communication regarding the task may be viewed with less importance; ultimately limiting cohesiveness between team members with regard to handling situations and managing relationships.

Highly optimistic teams, however, collectively believe that they have control over their own outcomes and their success. Teams sharing such beliefs regarding the overall quality of the team and their inherent reliance on each other to carry out the task successfully are more likely to report higher levels of cohesion (Cannon-Bowers, Salas, Blickensderfer, \& Bowers, 1998). Based on many of the same arguments, teams holding strong beliefs regarding the possibility of continued team success and a shared responsibility for the team's "destiny" are likely to foster satisfied team members who view their team as a primary means toward recognition and reward in their organization.

Team optimism may also serve to limit the levels of conflict experienced by teams. If conflict is conceptualized as interpersonal disagreement and divergence that causes rifts or dissatisfaction among team members, optimism may buffer the effects of conflict by establishing a norm within the team that, like difficult tasks, conflict among team members will be resolved. Additionally, optimistic teams displaying an increased sense of internal control over the situation (Seligman \& Schulman, 1986) should come to view themselves as capable of resolving conflict.

\section{Team resilience}

Resilience is an adaptive system which enables an individual to rebound or "bounce back" from a setback or failure (Coutu, 2002). A principle component of resilience as applied to the workplace is that after a negative event the employee rebounds to a higher level of motivation, rebounding beyond homeostasis (Richardson, 2002). Common themes of resilient individuals are recognized to be: (a) a firm acceptance of reality, (b) a deep belief, often buttressed by strongly held values, that life is meaningful, and (c) an astounding ability to improvise and adapt to significant change (Coutu, 2002).

Conceptualized at the team level, team resilience serves to provide teams with the capacity to bounce back from failure, setbacks, conflicts, or any other threat to well being that a team may experience. Teams often face uncertainty in the form of incomplete information, which "makes it difficult to predict the future states of many factors associated with a team's environment or tasks" (Argote, 1982, p. 420). Gladstein and Reilly (1985) found that the presence of an external threat and the introduction of pressure significantly reduced the communication channels and the amount of information utilized by team members. Under these types of conditions, one might expect that a team would have difficulty coordinating tasks between team members, or establishing effective patters of cooperation whereby teammates request and provide information from the right individuals at the right times.

As stated by Beehr and O'Hara, "occupational stressors lead to psychological strains, at least for most people and under most conditions" (1995, p. 109). When operating in these types of situations many individuals begin to focus inward, losing focus of the team task, and the important interdepen- 
dencies that exist within most work teams (Driskell \& Salas, 1991). Considering the lack of communication and increased uncertainty regarding task roles, one might expect that teams facing high levels of threat or stress would not display high levels of cohesion. While a number of studies have empirically supported the deleterious effects of stress in teams (e.g., Driskell \& Salas, 1991), researchers have yet to find a solution. In teamwork environments which involve potential stressors, the combined effects of the issues described above likely act to inhibit team satisfaction, and hold the potential to lead to increased conflict due to miscommunication, poor role coordination, etc.

Team resilience may prove to be an important positive team level capacity that aids in the repair and rebound of teams when facing potentially stressful situations. Teams which display the ability to either thrive under high liability situations, improvise and adapt to significant change or stress, or simply recover from a negative experience are less likely to experience the potentially damaging effects of threatening situations.

The above sections presented rationale suggesting that POB capacities may influence important team outcomes and add to our understanding of team effectiveness in the workplace. Given the potential relationships that were highlighted between POB capacities and team outcomes, we present the following hypotheses.

Hypothesis 1: Teams with higher levels of POB capacities will report higher levels of cohesion after completing a team project than teams that are lower on these capacities.

Hypothesis 2: Teams with higher levels of POB capacities will report higher levels of cooperation after completing a team project than teams that are lower on these capacities.

Hypothesis 3: Teams with higher levels of $\mathrm{POB}$ capacities will report higher levels of coordination after completing a team project than teams that are lower on these capacities.

Hypothesis 4: Teams with higher levels of POB capacities will report higher levels of team satisfaction after completing a team project than teams that are lower on these capacities.

Hypothesis 5: Teams with higher levels of POB capacities will report lower levels of conflict after completing a team project than teams that are lower on these capacities.

\section{Time and development considerations}

The hypotheses presented above depict proposed patterns of relationships for the three highlighted team level positive capacities. However, the "tenure" of the team and amount of time the team has spent interacting may have implications for which team level positive capacities will emerge as important predictors of team level outcomes and what point in time this emergence may occur. Thus, newly formed teams have important implications for the study of team level phenomenon which may emerge as teams gain exposure to one another over time. In an effort to begin to address the multiple calls for increased investigation of both positive psychological capacities (e.g., Gully et al., 2002) as well as team level outcomes across time (e.g., Rousseau, 2000), we collected data from teams at two points in time. While there are many theories of team development (e.g., Gersick, 1991; Tuckman, 1965), it is sufficient for the purpose of this study to surmise that as teams spend more time together it is likely that the nature of their interactions may develop/change. However, given the novelty of the above suggestions and the lack of previous research on the development of positive psychological capacities over time, we stop short of designing specific hypothesis regarding changes in psychologi- 
cal capacities over time. In addition, the design of the current study would offer little control over the specific types of experiences (e.g., setbacks, opportunities to obtain feedback) that are required to develop such capacities. Thus, for the purposes of this study, we investigate emergence of positive psychological capacities at two time periods without directly investigating time as a predictor of change.

\section{Methods}

\section{Participants}

The sample was comprised of 50.8 per cent male and primarily white ( 87.8 per cent) students with an average age of 23 years old. Data was collected from a total of 343 students (112 three or four person teams), however, only teams with complete participation at both time periods were included in the analyses. Thus, the reduced sample included for analysis consisted of 308 students from various upper- level management courses at a large Midwestern University who were divided into 101 three to four person teams. A total of 11 teams were excluded from the analysis primarily due to reasons such as a team member being absent from class on a project day due to illness, and two students opting to complete an alternative assignment instead of completing the research surveys.

\section{Procedure}

Participants were randomly assigned to teams at the beginning of the semester such that individuals sitting next to each other in class would not be assigned to the same team. In addition, assigned seating charts limited the opportunity for teammate interpersonal interactions when not actively working on team projects. In this way, two seating charts were used so that students only sat with their teammates during the in-class team projects and were not in physical proximity to one another during normal class sessions when teams did not meet to complete a task.

During the course of the semester, each team completed an identical series of four in-class (approximately 75 minutes per project) team projects relevant to course material. The projects used in this study are best defined as case-based decision-making projects where teammates were asked to discuss and develop solutions to situations that were relevant to their course material. Participants were notified that everyone within a given team would receive the same grade for each project. In an effort to understand the impact of psychological capacities on newly formed teams, participants were asked to complete items on a questionnaire regarding the interdependency of the task, team outcomes, and POB capacities. Questionnaires were collected after the completion of the first team project as it would not be reasonable to expect any level of experience-based collective agreement on the various POB capacities prior to the teams actually having the opportunity to interact. Prior to completing the fourth (and final) team task, participants were again asked to complete a paper and pencil questionnaire containing measures of the team's POB capacities. Following completion of the final task, participants then responded to measures tapping into their perceptions of the team's level of cohesiveness, cooperation, coordination, conflict, and satisfaction. Measures were collected in this manner to determine if team POB capacities going into the final project would be related to team perceptions of the various outcome measures after completion of the task. In addition, we were interested in investigating any shifts in the patterns of relationships between the initial team meeting and the final team meeting that may have occurred due to increased team interactions over time. 


\section{Measures}

\section{Previous teammate knowledge}

Two items were used to control for prior team interaction: "To what extent have you interacted with each of your teammates before the beginning of the first project," and "To what extent did you know each of your teammates before the beginning of the project."

\section{Task and outcome interdependency}

Levels of interdependence experienced during the two tasks were assessed using two three-item scales (task interdependence and outcome interdependence) from Campion et al., 1993. Both scales have adequate reliability and were used as a manipulation check to ensure that the in-class projects were experienced as interdependent tasks $(\alpha=.85)$.

\section{POB team capacities}

Team optimism, team efficacy, and team resilience were measured using adapted items from the PsyCap questionnaire (PCQ) (Luthans et al., 2007). The items used in the PCQ were drawn from published validated scales commonly used in positive psychology. Each of the three capacities utilized in this study were represented by six items in the PCQ. In order to measure these constructs as an assessment of a team's capacity rather than as a collection of individual capacities, each item was adapted to fit a referent-shift approach (Chan, 1998) whereby the target of each item was the team rather than the individual. Sample items for each of the scales include: "My team is confident setting targets/goals for our project work" (efficacy); "Our team always looks on the bright side of things regarding our projects" (optimism); and "Our team usually manages difficulties one way or another when working" (resiliency). All responses for the PCQ are anchored on a 6-point Likert scale ranging from strongly disagree to strongly agree. Each of the capacities has demonstrated acceptable reliability in past studies (e.g., Avey, Patera, \& West, 2006) and displayed acceptable reliability at both data collection points (team project-1 $\alpha$ 's: team efficacy $=.94$, team resilience $=.76$, team optimism $=.83$; team project- $4 \alpha^{\prime}$ s: team efficacy $=.96$, team resilience $=$ .76 , team optimism $=.75$ ).

It was discussed earlier that the nature of the team level POB capacities are best represented by a collectively agreed upon rating of each construct within each team (composition model, Chan, 1998). Thus, rater agreement $\left(r_{w g}\right)$ was calculated for each of the POB capacities in order to determine if there was adequate within-team agreement (i.e., .70) to justify aggregation to the team level (James, DeMaree, \& Wolf, 1984). The outcomes of these analyses are discussed in the results section below.

\section{Team process outcomes}

Team cohesion was measured using a combination of items from Seashore (1954) and Carron, Widmeyer, \& Brawley (1985). Item stems remained at the team level in order to maintain the team focus. Consistent with all process variables, cohesion (as a team level construct) was treated as an additive model (Chan, 1998). In the present study, the focus is not on the level of agreement of the cohesiveness of the group, rather on the overall level of cohesion that exists in the group at any given point when data is collected. As a result, cohesion (along with the remaining process-outcome variables discussed below) was treated as a team level variable represented by an average score of the individual team member's responses. Responses were provided on a 5-point Likert scale ranging from strongly disagree to strongly agree. Reliability for this scale was acceptable for measurement at both project-1 (.73) and project-4 (.79). 
Team conflict was measured using a 4-item scale developed by Jehn (1995) to measure interpersonal conflict within teams. Reliability for this scale has been shown to be fairly high (.92). Responses were on a 5-point Likert scale ranging from 1-none to 5-a lot. Alphas for the team-conflict scale were adequate for project-1 (.90) and project-4 (.94).

Team cooperation was measured using a 5-item measure developed by Mumford, Campion, and Morgeson (2006). This cooperation scale taps into concepts regarding teammate's willingness to share information and to assist each other's work. Sample items include, "Members of my team are very willing to share information with other team members," and "Members of my team help each other out on the project when needed." Alphas for this study were also acceptable for both collection periods (project-1: .89; project-4: .94).

Team coordination was measured using a scale developed by Georgopoulos and Mann (1962). The scale consists of seven items that were adapted for this study to address the activities of a general project team. Georgopoulos and Mann (1962) provide evidence for adequate reliability (>.70) and for construct/content validity as well. Alphas for this study were acceptable (project-1, .88; project-4, .93).

The extent to which individuals were satisfied with their team was measured with four items developed by a Team Effectiveness Laboratory operating at a large Midwestern University. Examples of these items include, "To what extent would you like to remain a member of this team?" and "How satisfied are you with the overall performance of your team?" Previous use of these items has resulted in acceptable reliability (.72) and responses to these items have shown favorable convergent validity with a global measure of job satisfaction (Job in General Scale) (Ironson, Smith, Brannick, Gibson, \& Paul, 1989). These items were measured with a 5-point scale and were aggregated as an average based on the additive model previously discussed. Alphas for both data collection points were acceptable (project-1, .70; project-4, .73).

\section{Results}

\section{Teammate knowledge and task interdependency}

Tests of prior knowledge/interactions with teammates revealed that the random assignment of individuals to teams was successful in eliminating prior working or interactive experience among teammates [project-1: $M=1.13$ (6-point scale), standard deviation $(\mathrm{SD})=.32$ ]. This result supported the notion that team level findings in this study were primarily the result of phenomenon that emerged during the team-task process and were not heavily influenced by pre-existing relationships among teammates.

A key concern for this study was whether the nature of the tasks involved an adequate degree of interdependence among teammates. The level of interactions/consultation associated with interdependent tasks has implications for (1) the level of individual agreement on team level characteristics such as optimism, and (2) the extent to which a team level representation of such a construct would have an impact on team processes. Results (based on a 5-point scale) suggest that participants perceived the assigned in-class team projects to involve above average levels of interdependency (project$1: M=3.46, \mathrm{SD}=.47$; project- $4: M=3.54, \mathrm{SD}=.54$ ). Although average responses were not extremely high, these results provide assurance that the assigned tasks required a level of interaction that was likely to lead to collective perception and possible team level influence on outcomes. 


\section{Team level POB capacity emergence}

Constructs that require a degree of collective agreement prior to being aggregated and conceptually treated as a team level variable should display minimum rater agreement levels of approximately .70 (James et al., 1984). For each POB capacity, $r_{\text {wg }}$ was calculated separately for both project- 1 and project- 4 data. Results suggested adequate within-team rater agreement at both data collection points for team optimism (project-1: $r_{\mathrm{wg}}=.91$; project- $4: r_{\mathrm{wg}}=.89$ ). However, for both team efficacy and team resilience, rater agreement was only acceptable based on the .70 standard at project- 4 (project-1: efficacy, $r_{\mathrm{wg}}=.62$; resilience, $r_{\mathrm{wg}}=.58$; project- 4 : efficacy, $r_{\mathrm{wg}}=.86$; resilience, $r_{\mathrm{wg}}=.79$ ).

The results for team efficacy and team resilience at project- 1 may not be surprising. Developing collective agreement within a team for these two constructs is likely to require experience completing tasks (i.e., efficacy) and the experience of challenges or setbacks (i.e., resilience). Conversely, the extent to which teammates express optimism does not seem to be contingent upon specific time or interaction requirements. Potentially, a team comprised of strangers may immediately begin talking about their expectations and goals for the team, during which time they directly or indirectly express the extent to which they feel that the team is in control of the output/outcome. Through such a process, teammates may quickly ascertain a shared sense of optimism within their team. While it is possible that a sense of efficacy or resilience could also be espoused via verbal communication prior to any task- based experience, the process of discussing expectations and level of control over a situation (optimism) seems anecdotally more common than immediately sharing one's own belief in their own abilities (efficacy) or discussing one's level of resilience to setbacks.

Although the levels of rater agreement were below standard at project- 1 for team efficacy and team resilience, the results still suggest more within team agreement than disagreement (i.e., above .50). For this reason, and for comparison with data from project-4, both team efficacy and team resilience were aggregated and included in analyses for project-1. However it is worth noting that the results presented above tempered our willingness to strongly interpret any findings for these two capacities during project-1.

\section{Tests of hypotheses}

Means, SDs, and intercorrelations among variables at both time periods are included in Tables 1 and 2. All five hypotheses were tested separately for team projects 1 and 4 .

Analysis of hypotheses for project- 1 data consisted of linear regression tests whereby each of the three team level positive capacities measured after project- 1 were simultaneously entered into the model to predict a particular team level outcome variable that was also measured during the project-1 data collection period. Analysis of the project-4 data differed slightly. For these analyses, hierarchical regression was used to control for project- 1 levels of cohesion, cooperation, coordination, conflict, and satisfaction. POB capacities were subsequently entered into the model to assess relationships with team outcome variables measured after project-4. Again, the POB capacities for this set of analyses were collected prior to the teams' interactions, whereas the team outcome variables were collected after the team project was completed. Results of all regression analyses may be found in Tables 3 and 4. Our first hypothesis proposed that teams with higher levels of POB capacities would also report higher levels of cohesion. The results for the analysis of the project- 1 data show that the combination of the three POB capacities explained a significant amount of variance in cohesion $\left(R^{2}=.30, p<.01\right)$, however the only significant individual predictor was team optimism $(\beta$ $=.49, p<.01)$. Results for the analysis of the project- 4 data also displayed overall model significance for the three POB capacities, even after controlling for previous levels of cohesion reported after the 
Table 1. Means, standard deviations, and intercorrelations among variables of interest: project-1

\begin{tabular}{|c|c|c|c|c|c|c|c|c|c|c|c|}
\hline Variable & Mean & SD & $\alpha$ & 1 & 2 & 3 & 4 & 5 & 6 & 7 & 8 \\
\hline \multicolumn{12}{|l|}{ Session 1} \\
\hline 1. Team efficacy & 4.71 & 0.44 & .94 & - & & & & & & & \\
\hline 2. Team optimism & 4.68 & 0.41 & .83 & $.70^{*}$ & - & & & & & & \\
\hline 3. Team resilience & 4.63 & 0.39 & .76 & $.70^{*}$ & $.69^{*}$ & - & & & & & \\
\hline 4. Team cohesion & 3.36 & 0.28 & .73 & $.41^{*}$ & $.54^{*}$ & $.43^{*}$ & - & & & & \\
\hline 5. Team cooperation & 3.86 & 0.33 & .89 & $.33^{*}$ & $.46^{*}$ & $.37^{*}$ & $.68^{*}$ & - & & & \\
\hline 6. Team coordination & 3.37 & 0.49 & .88 & $.50^{*}$ & $.56^{*}$ & $.54^{*}$ & $.58^{*}$ & $.60^{*}$ & - & & \\
\hline 7. Team conflict & 1.54 & 0.36 & .90 & $-.17^{*}$ & $-.22^{*}$ & $-.21^{*}$ & $-.41^{*}$ & $-.45^{*}$ & $-.40^{*}$ & - & \\
\hline 8. Team satisfaction & 3.62 & 0.49 & .70 & $.46^{*}$ & $.53^{*}$ & $.53^{*}$ & $.52^{*}$ & $.59^{*}$ & $.74^{*}$ & $-.45^{*}$ & - \\
\hline
\end{tabular}

Team $N=101$.

* Correlation is significant at the $p<.05$ level (two-tailed).

first team project $\left(\Delta R^{2}=.34, p<.01\right)$. However, at this later stage in the teams' interaction histories team resilience was the only significant predictor $(\beta=.35, p<.05)$. These results suggest that, at initial team formation, team optimism is most strongly related to cohesion. However, after teams have interacted over more points in time, their capacity for resilience when faced with challenges is better able to explain the extent to which they feel tightly knit as a team. Thus, Hypothesis 1 was only partially supported.

Hypothesis 2 proposed that teams with higher levels of POB capacities would also report higher levels of cooperation. Analysis of the project- 1 data show that the combination of the three POB capacities explained a significant amount of variance in cooperation $\left(R^{2}=.27, p<.01\right)$, but that the only significant individual predictor was again team optimism $(\beta=.43, p<.01)$. After controlling for previously reported levels of cooperation, results for the analysis of the project- 4 data also displayed overall model significance for the three $\mathrm{POB}$ capacities $\left(\Delta R^{2}=.65, p<.01\right)$. However, at this later stage in the team's tenure, both team efficacy $(\beta=.45, p<.01)$ and team resilience $(\beta=.52, p<.01)$ displayed significant relationships with cooperation. Similar to Hypothesis 1, team optimism appeared as the primary predictor of cooperation when teams were newly formed, but team efficacy and team resilience were more strongly related after the teams had the opportunity to interact. Overall, these findings provide partial support for Hypothesis 2.

Table 2. Means, standard deviations, and intercorrelations among variables of interest: project-4

\begin{tabular}{|c|c|c|c|c|c|c|c|c|c|c|c|}
\hline Variable & Mean & SD & $\alpha$ & 1 & 2 & 3 & 4 & 5 & 6 & 7 & 8 \\
\hline \multicolumn{12}{|l|}{ Session 4} \\
\hline 1. Team efficacy & 4.83 & 0.45 & .96 & - & & & & & & & \\
\hline 2. Team optimism & 4.46 & 0.45 & .75 & $.66^{*}$ & - & & & & & & \\
\hline 3. Team resilience & 4.63 & 0.44 & .76 & $.76^{*}$ & $.76^{*}$ & - & & & & & \\
\hline 4. Team cohesion & 3.43 & 0.27 & .79 & $.33^{*}$ & $.39^{*}$ & $.40^{*}$ & - & & & & \\
\hline 5. Team cooperation & 3.95 & 0.36 & .94 & $.47^{*}$ & $.42^{*}$ & $.49^{*}$ & $.60^{*}$ & - & & & \\
\hline 6. Team coordination & 3.52 & 0.49 & .93 & $.40^{*}$ & $.52^{*}$ & $.55^{*}$ & $.49^{*}$ & $.60^{*}$ & - & & \\
\hline 7. Team conflict & 1.74 & 0.57 & .94 & $-.35^{*}$ & -.37 & $-.42^{*}$ & $-.27^{*}$ & $-.33^{*}$ & $-.22^{*}$ & - & \\
\hline 8. Team satisfaction & 3.62 & 0.49 & .73 & $.47^{*}$ & $.50^{*}$ & $.52^{*}$ & $.50^{*}$ & $.42^{*}$ & $.64^{*}$ & $-.21^{*}$ & - \\
\hline
\end{tabular}

Team $N=101$.

* Correlation is significant at the $p<.05$ level (2-tailed). 
Table 3. Project time 1 regression results for all hypotheses

\begin{tabular}{|c|c|c|c|c|}
\hline & $\beta$ & $r$ & $R^{2}$ & $F$ \\
\hline \multicolumn{5}{|c|}{ Hypothesis 1 dependent variable: cohesion } \\
\hline Step 1 & & .55 & .30 & $14.91^{* *}$ \\
\hline Team efficacy & .03 & & & \\
\hline Team optimism & $.49^{* *}$ & & & \\
\hline Team resilience & .06 & & & \\
\hline \multicolumn{5}{|c|}{ Hypothesis 2 dependent variable: cooperation } \\
\hline Step 1 & & .52 & .27 & $12.88^{* *}$ \\
\hline Team efficacy & -.04 & & & \\
\hline Team optimism & $.43^{* *}$ & & & \\
\hline Team resilience & .15 & & & \\
\hline \multicolumn{5}{|c|}{ Hypothesis 3 dependent variable: coordination } \\
\hline Step 1 & & .57 & .33 & $16.82^{* *}$ \\
\hline Team efficacy & .14 & & & \\
\hline Team optimism & .31. & & & \\
\hline Team resilience & .19 & & & \\
\hline \multicolumn{5}{|c|}{ Hypothesis 4 dependent variable: satisfaction } \\
\hline Step 1 & & .55 & .30 & $15.04^{* *}$ \\
\hline Team efficacy & .06 & & & \\
\hline Team optimism & $.32^{*}$ & & & \\
\hline Team resilience & .23 & & & \\
\hline \multicolumn{5}{|c|}{ Hypothesis 5 dependent variable: conflict } \\
\hline Step 1 & & .33 & .11 & $5.99^{* *}$ \\
\hline Team efficacy & -.04 & & & \\
\hline Team optimism & -.21 & & & \\
\hline Team resilience & -.10 & & & \\
\hline
\end{tabular}

${ }^{*} p<.05 ;{ }^{* *} p<.01$.

Hypothesis 3 proposed that teams with higher levels of POB capacities would report higher levels of coordination. The results for the analysis of the project- 1 data show that the combination of the three POB capacities explained a significant amount of variance in coordination $\left(R^{2}=.33, p<.01\right)$, but that the only significant individual predictor was once again team optimism $(\beta=.31, p<.05)$. After controlling for previously reported levels of coordination, results for the analysis of the project- 4 data also displayed overall model significance for the three POB capacities $\left(\Delta R^{2}=.25, p<.01\right)$. However, the only significant individual predictor remained team optimism $(\beta=.39, p<.01)$. With regard to coordination, it appears that teams' expectations for positive results and beliefs in internal control are more important than team efficacy and team resilience. These findings provide partial support for Hypothesis 3.

Hypothesis 4 proposed that teams with higher levels of POB capacities would report higher levels of team satisfaction. Analysis of the project- 1 data showed that the combination of the three POB capacities explained a significant amount of variance in team satisfaction $\left(R^{2}=.30, p<.05\right)$, but that the only significant individual predictor was, yet again, team optimism $(\beta=.32, p<.05)$. After controlling for previously reported levels of team satisfaction, results for the analysis of the project- 4 data also displayed overall model significance for the three POB capacities $\left(\Delta R^{2}=.40, p<.01\right)$. Again, the only significant individual predictor was team optimism $(\beta=.53, p<.01)$. Thus, Hypothesis 4 was only partially supported. 
Table 4. Project time 4 regression results for all hypotheses

\begin{tabular}{|c|c|c|c|c|}
\hline & $\beta$ & $R^{2}$ & $\Delta R^{2}$ & $F$ \\
\hline \multicolumn{5}{|c|}{ Hypothesis 1 dependent variable: cohesion } \\
\hline Step 1 & & .25 & .25 & $21.08 * *$ \\
\hline Cohesion at T1 & $.20^{*}$ & & & \\
\hline Step 2 & & .59 & .34 & $16.87^{* *}$ \\
\hline Team efficacy & .11 & & & \\
\hline Team optimism & .25 & & & \\
\hline Team resilience & $.35^{*}$ & & & \\
\hline \multicolumn{5}{|c|}{ Hypothesis 2 dependent variable: cooperation } \\
\hline Step 1 & & .17 & .17 & $12.87^{* *}$ \\
\hline Cooperation at T1 & -.04 & & & \\
\hline Step 2 & & .90 & .65 & $65.42 * *$ \\
\hline Team efficacy & $.45^{* *}$ & & & \\
\hline Team optimism & -.01 & & & \\
\hline Team resilience & $.52 * *$ & & & \\
\hline \multicolumn{5}{|c|}{ Hypothesis 3 dependent variable: coordination } \\
\hline Step 1 & & .34 & .34 & $33.71^{* *}$ \\
\hline Coordination at $\mathrm{T} 1$ & $.31^{* *}$ & & & \\
\hline Step 2 & & .60 & .25 & $12.69 * *$ \\
\hline Team efficacy & .12 & & & \\
\hline Team optimism & $.39 * *$ & & & \\
\hline Team resilience & .11 & & & \\
\hline \multicolumn{5}{|c|}{ Hypothesis 4 dependent variable: satisfaction } \\
\hline Step 1 & & .11 & .11 & $7.82^{* *}$ \\
\hline Satisfaction at T1 & .08 & & & \\
\hline Step 2 & & .51 & .40 & $16.68^{* *}$ \\
\hline Team efficacy & .17 & & & \\
\hline Team optimism & $.53^{* *}$ & & & \\
\hline Team resilience & .01 & & & \\
\hline \multicolumn{5}{|c|}{ Hypothesis 5 dependent variable: conflict } \\
\hline Step 1 & & .04 & .04 & 2.46 \\
\hline Conflict at $\mathrm{T} 1$ & .08 & & & \\
\hline Step 2 & & .31 & .28 & $11.63^{* *}$ \\
\hline Team efficacy & -.11 & & & \\
\hline Team optimism & -.17 & & & \\
\hline Team resilience & -.26 & & & \\
\hline
\end{tabular}

Betas reported from final model at Step 2.

${ }^{*} p<.05 ;{ }^{* *} p<.01$.

Hypothesis 5 proposed that teams with higher levels of POB capacities would report lower levels of conflict. The analysis of the project- 1 data showed that the combination of the three POB capacities explained a significant amount of variance in conflict $\left(R^{2}=.11, p<.05\right)$, but that none of the individual POB capacities accounted for unique variance in conflict. After controlling for previously reported levels of conflict, analysis of the project- 4 data also displayed overall model significance for the three POB capacities $\left(\Delta R^{2}=.28, p<.01\right)$. Similar to the analysis of the project- 1 data, none of the individual POB capacities accounted for unique variance in conflict. Despite the fact that team status on the three POB capacities combined to account for significant variation in levels of reported conflict, none of the POB capacities individually accounted for significant variance. Thus, Hypothesis 5 was not supported. 


\section{Discussion}

Given the recent movement toward rethinking organizational psychology from a positive perspective, it is a natural transition to begin to expand our conceptualization of what have traditionally been treated as individual level POB constructs to higher levels in organizations, including but not restricted to teams. This study represents an attempt to empirically examine the potential relationships between positive psychological capacities conceptualized as team level constructs, and important team level outcomes. We found that self-efficacy, optimism, and resilience, which have all been found to impact positive individual level outcomes, also functioned as team level capacities representing an agreed- upon level of team efficacy, team optimism, and team resilience. Overall, however, the results provided mixed support for the stated hypotheses. Team optimism appeared to be the most functional team level POB capacity for newly formed teams given its significant relationship with four of the five team outcomes that were tested. Team efficacy and team resilience both were related to important team outcomes as well, but only at the time of project- 4 data collection after teams had considerably more time to interact with each other. The differential findings between the two time periods were particularly interesting and suggest that the nature of the influence of team level POB capacities is not simply a "more is better" equation. Instead, it appears that the extent to which specific team level POB capacities influence team processes and outcomes may be dependent on the level of interactions between teammates. In sum, while the pervasiveness of the relationships proposed between each positive psychological capacity and each of the team outcomes was not supported, we did find strong specific relationships between particular positive capacities and team outcomes. Implications of these findings for research and practice are discussed below.

\section{Research implications}

Given the treatment of POB capacities as state-like (Luthans, 2002b), one may initially question whether teams are likely to come to a sufficient level of collective agreement on capacities which may fluctuate over time. Results of this study provide evidence that, despite their state-like nature, positive psychological capacities do prove capable of being conceptualized as a shared team level construct at a given point in time. Although this finding has been fairly well established for collective efficacy (e.g., Gully et al., 2002), the degree to which positive psychological capacities such as optimism and resilience could be thought of as collective constructs has largely been ignored.

The potential impact of team level positive capacities was also highlighted in this study by the large amounts of variance explained in the team outcomes. For example, after controlling for previous levels of a given outcome (e.g., project-1 cohesion), team level POB constructs proved capable of explaining significant incremental variance in four of the five outcome variables. Given established links between the team outcome variables in the present study and team performance (e.g., cohesion and performance, Mullen \& Copper, 1994; cooperation and performance, Porter, Hollenbeck, Ilgen, Ellis, West, \& Moon, 2003; coordination and performance, Wagner, 1995; conflict and performance, Jehn, 1995; satisfaction with turnover/performance, Ivancevich \& Matteson, 1980) these findings suggest that the treatment of these and other positive psychological capacities at the team level holds potential for future research.

A particularly interesting finding of this study highlighted the importance of time and amount of team interaction when considering the potential impact of team level positive capacities on team level outcomes. Results from the project-1 data analysis revealed that only team optimism displayed adequate rater agreement to justify aggregation to the team level. However, after teams had interacted over multiple team projects, team efficacy and team resilience, along with team optimism dis- 
played adequate levels of within team rater agreement. This finding suggests that the types of team level capacities which emerge as agreed upon and functional capacities of a team may change as teams develop.

Results from the team outcome analyses supported the notion that different POB capacities functioned more strongly depending on the amount of interaction among teammates. Although we expected that the strength of the relationships between the POB capacities and team outcomes would be stronger after teams had been given the opportunity to work together across multiple occasions, the extent of the differential effects between the two time periods was not anticipated. Perhaps not surprising, given the lack of agreement on team efficacy and team resilience in the project- 1 data, the only team level positive capacity that acted as a significant predictor of team outcomes in the project-1 data was team optimism. The remaining POB capacities may have lacked the necessary level of agreement among teammates in order to have a meaningful impact on team processes at initial team formation. Instead, team processes were largely related to the extent to which teams were optimistic about their outcomes and their ability to control their own fate. Conversely, during project-4, while team optimism was still related to team satisfaction and coordination, cohesion seemed primarily dependent on the extent to which teams felt that they were capable of dealing with setbacks and rebounding from challenges, a perception that likely required increased interactions with a team to develop. Similarly, cooperation was strongly related to both the extent of team efficacy (i.e., confident teams believed in their abilities and were more willing to cooperate with other capable members to get the job done), and team resilience (i.e., teams capable of rebounding from setbacks and challenges are more likely to remain helpful toward other teammates and to maintain lines of communication rather than withdrawing from their team and focusing inward).

One potential implication of the project-to-project differences that were found in this study is that researchers interested in investigating positive constructs such as team resilience may need to provide teams with adequate interactive experiences. Failing to do so may result in the dismissal of potentially beneficial positive psychological capacities simply as a result of only investigating newly formed or temporary teams (as is common practice in many laboratory-based team studies). On the other hand, if interested in studying newly formed teams, researchers may be wise to focus on positive predictors such as team optimism that are more likely to emerge at the collective level after minimal interaction. Also, the differences found between project- 1 and project- 4 data in this study generally imply that the nature of POB or positive psychological capacities may differ for teams which have spent many years together, or teams which are newly formed but include teammates who have a history of interaction with one another. Researchers must be careful when considering the types of POB or positive psychological capacities to be included in their studies given the nature of the work teams under investigation.

\section{Practical implications}

It has been suggested that training directed specifically at team level capacities may provide unique benefits over and above individual level training. This may be especially true if the training can be conducted for individuals while operating as a team. Given the possible relationships with important team level processes reported in this study, organizations may benefit from developing teams that are optimistic about their likelihood of success (optimism), are confident in their capabilities (efficacy), and are capable of rebounding from setbacks (resilience).

In addition, organizations have become increasingly concerned with the costs of absenteeism and turnover (Harrison \& Mantocchio, 1998). Given earlier statements regarding the increased restructuring of work around teams, it is natural to assume that individuals' affective experiences working in 
teams may lead to absenteeism behavior and turnover. Recent work by Avey et al., 2006 found that the POB capacities of optimism, resilience, and efficacy were related to decreased levels of absenteeism. Development of these team level positive capacities may have a similar impact on individuals' desire to leave their team. For example, given previous research which suggests that team satisfaction predicts intent to leave the team (Jinnett \& Alexander, 1999), it is possible that increasing team optimism, and thereby increasing team satisfaction, will help to retain important team members. Future research should investigate these possible links and the impact of team level POB capacities on turnover and absenteeism behavior.

\section{Limitations and suggestions for future research}

The student sample used for this study specifically allowed for us to control for prior team member interactions and to track teams from their initial formation (a sample characteristic which is not easily obtained in an organizational setting with ongoing teams already established). However, it is possible that teams formed in an organizational setting have had extensive prior interaction; thus accelerating or modifying the emergence of positive psychological capacitates. In addition, a secure classroom setting may not be conducive to the types of challenges or the levels of perceived importance of outcomes (e.g., career security) that are faced by work teams in organizations. However, previous research has shown that the correlation between effect sizes obtained in non-field/laboratory and field settings generally exceed .70; suggesting that the use of a student sample may not detrimentally affect generalizability (Anderson, Lindsay, \& Bushman, 1999). Furthermore, we could argue that the results reported in this study may be an underestimate of the population effect size. The positive influence or buffering effects of team POB capacities on team processes and outcomes may be more important and more pronounced in field settings where the implications and importance of team-based work processes and outcomes are amplified, potentially increasing the importance of team characteristics such as efficacy and resilience. Nevertheless, results of this study should be interpreted with caution until the generalizability of the findings has been established through replication in different organizational contexts.

An additional possible concern regarding the sample utilized in this study is the degree of homogeneity. However, evidence provided by Klein, Conn, Smith, and Sorra (2001) suggests that demographic heterogeneity (with respect to age, education, pay, tenure, and gender) within a group did not greatly affect group members' perceptions of the work environment and did not yield too much group variability in the survey responses. Despite these findings, it is still possible that our results may have differed given a more diverse sample in terms of ethnicity or international culture. Thus, future research should investigate the effects of team level positivity with more diverse samples to understand how the results may differ.

The project-to-project changes evident in the pattern of results suggest that the influence of positive psychological capacities at the team level is likely a complex story that warrants future research. Specifically, future work is needed to investigate both on-going organizational work teams and work teams with fluid team membership in order to determine how teams develop positive capacities, and if and how such capacities are bolstered or maintained. Future research is also needed to understand what types of situations may break down positive team capacities and how to buffer these potentially deleterious effects. In regard to teams with fluid membership, it may be that the removal or addition of certain team members may serve to drastically affect team level positive capacities. Additional research is needed in order to gain a better understanding of the dynamic relationship between team level positivity and important team/work outcomes. 
Finally, the methodological framework employed in this study limited our ability to utilize time as a direct predictor of team level outcomes. One suggested method would be to use multi-level modeling with time as a level one predictor. This method would allow researchers to draw conclusions on the specific effect that time has on team level efficacy, optimism, and resilience.

The findings of this study provide a first look at positive psychological capacities at the team level. Although teams have received increased attention over recent years, few authors have addressed the emergence of positive team level constructs. Overall, our findings suggest that organizations could potentially benefit from understanding how team positivity aids in the facilitation of team processes and outcomes. Furthermore, this study suggests that the scope of research involving positivity in the workplace should be expanded to investigate the influence of positivity at team, department, and organizational levels.

\section{The authors:}

Bradley J. West is the Assistant Director of Applied Research and Product Development for HUMANeX Ventures, a strategic human resource development firm. His primary research interests center on team development and leadership.

Jaime L. Patera is a doctoral student in the Department of Management at the University of Nebraska. She is also Assistant Director of Research and Impact Learning at HUMANeX Ventures, a strategic human resource development firm. Her primary research interests focus on follower-centered leadership, team dynamics and development, and the influence of positivity.

Melissa Carsten is an Assistant Professor at Winthrop University. Her research interests focus on leadership and followership in organizations and the role that implicit followership theories play in leader-follower interactions.

\section{References}

Anderson, C. A., Lindsay, J. J., \& Bushman, B. J. (1999). Research in the psychological laboratory: Truth or triviality? Current Directions in Psychological Science, 8, 3-9.

Argote, L. (1982). Input uncertainty and organizational coordination in hospital emergency units. Administrative Science Quarterly, 27, 420-434.

Avey, J. B., Patera, J. L., \& West, B. J. (2006). The implications of positive psychological capital on employee absenteeism. Journal of Organizational and Leadership Studies, 13, 42-60.

Avolio, B. J. (2005). Leadership development in balance: Made/Born. NJ: Erlbaum Associates.

Bandura, A. (1997). Self-efficacy: The exercise of control. New York: Freeman.

Barrick, M. R., Stewart, G. L., Neubert, M. J., \& Mount, M. K. (1998). Relating member ability and personality to workteam processes and team effectiveness. Journal of Applied Psychology, 83, 377-391.

Beehr, T. A., \& O'Hara, K. (1995). Methodological designs for the evaluation of occupational stress interventions: Preview. In S. V. Kasl, \& C. L. Cooper (Eds.), Stress and health: Issues in research methodology (pp. 79-112). Oxford, England: John Wiley \& Sons.

Cameron, K. S., Dutton, J. E., \& Quinn, R. (2003). Positive organizational scholarship. San Francisco: Berrett- Koehler.

Campion, M. A., Medsker, G. J., \& Higgs, A. C. (1993). Relations between work group characteristics and effectiveness: Implications for designing effective work groups. Personnel Psychology, 46, 823-850.

Carver, C. S., \& Scheier, M. S. (2003). Optimism. In C. R. Snyder, \& S. J. Lopez (Eds.), Handbook of positive psychology (pp. 231-243). Oxford, UK: Oxford University Press.

Cannon-Bowers, J. A., Salas, E., Blickensderfer, E., \& Bowers, C. A. (1998). Impact of cross training and workload on team functioning: A replication and extension of initial findings. Human Factors, 40, 92-101. 
Carron, A. V., Widmeyer, W. N., \& Brawley, L. R. (1985). The development of an instrument to assess cohesion in sport teams: The group environment questionnaire. Journal of Sport-Psychology, 7, 244-266.

Center for Creative Leadership. (2006). CCL poll: Teams in organizations. Retrieved December 1, 2006, from CCL website, http://www.ccl.org/leadership/enewsletter/2006/SEPaugpollresultsaspx?pageId=1757

Chan, D. (1998). Functional relations among constructs in the same content domain at different levels of analysis: A typology of composition models. Journal of Applied Psychology, 83, 234-246.

Compton, W. C. (2005). Introduction to positive psychology. Belmont, CA, US: Thomson Wadsworth.

Coutu, D. L. (2002). How resilience works. Harvard Business Review, May, 46-55.

Crampton, S. M., \& Wagner, J. A. (1994). Percept-percept inflation in microorganizational research: An investigation of prevalence and effect. Journal of Applied Psychology, 79, 67-76.

Day, D. V. (2000). Leadership development: A review in context. The Leadership Quarterly, 11, 581-613.

Driskell, J. E., \& Salas, E. (1991). Group decision making under stress. Journal of Applied Psychology, 76, 473- 478.

Gersick, C. J. (1991). Revolutionary change theories: A multilevel exploration of the punctuated equilibrium paradigm. Academy of Management Review, 16, 10-36.

Georgopoulos, B. S., \& Mann, F. C. (1962). The community general hospital. New York, NY: Macmillan.

Gibson, C. B. (1999). Do they do what they believe they can? Group efficacy and group effectiveness across tasks and cultures. Academy of Management Journal, 42, 138-152.

Gladstein, D. L., \& Reilly, N. P. (1985). Group decision making under threat: The tycoon game. Academy of Management Journal, 28, 613-627.

Gully, S. M., Incalcaterra, K. A., Joshi, A., \& Beauien, M. J. (2002). A meta-analysis of team-efficacy, potency, and performance: Interdependence and level of analysis as moderators of observed relationships. Journal of Applied Psychology, 87, 819-832.

Guzzo, R. A., \& Shea, G. P. (1992). Group performance and intergroup relations in organizations. In M. D. Dunnette, \& L. M. Hough (Eds.), Handbook of industrial and organizational psychology (Vol. 3, 2nd ed., pp. 269-313). Palo Alto, CA: Consulting Psychologists Press, Inc.

Harrison, D. A., \& Mantocchio, J. J. (1998). Time for absenteeism: A twenty year review of origins, offshoots, and outcomes. Journal of Management, 24, 305-350.

Ilgen, D. R., Major, D. A., Hollenbeck, J. R., \& Sego, D. J. (1993). Team research in the 1990s. In M. M. Chemers, \& R. Ayman (Eds.), Leadership theory and research (pp. 245-270). New York: Academic Press.

Ironson, G. H., Smith, P. C., Brannick, M. J., Gibson, W. N., \& Paul, K. B. (1989). Construction of a job in general scale: A comparison of global, composite, and specific measures. Journal of Applied Psychology, 74, 197-200.

Ivancevich, J., \& Matteson, M. T. (1980). Stress and work: A managerial perspective. Glenvian, IL: Scott Foresman.

James, L. R., Demaree, R. G., \& Wolf, G. (1984). Estimating within group interratter reliability with and without response bias. Journal of Applied Psychology, 69, 85-98.

Jehn, K. A. (1995). A multi-method examination of the benefits and detriments of intragroup conflict. Administrative Science Quarterly, 40, 256-282.

Jinnett, K., \& Alexander, J. A. (1999). The influence of organizational context on quitting intention: An examination of treatment staff in long-term mental health care settings. Research on Aging, 21, 176-204.

Katz-Navon, T. Y., \& Erez, M. (2005). When collective-and self-efficacy affect team performance: The role of task interdependence. Small Group Research, 36, 437-465.

Klein, K. J., Conn, A. B., Smith, B. D., \& Sorry, J. S. (2001). Is everyone in agreement? An exploration of within- group agreement in employee perceptions of the work environment. Journal of Applied Psychology, 86, 3-16.

Kozlowski, S. J. W., \& Bell, B. S. (2003). Work groups and teams in organizations. In W. C. Borman, D. R. Ilgen, \& R. Klimoski (Eds.), Comprehensive handbook of psychology (Vol. 12, pp. 333-376). New York: Wiley.

Kozlowski, S. W. J., Gully, S. M., Nason, E. R., \& Smith, E. M. (1999). Developing adaptive teams: A theory of compilation and performance across levels and time. In D. R. Ilgen, \& E. D. Pulakos (Eds.), The changing nature of performance: Implications for staffing, motivation, and development (pp. 240-292). San Francisco, CA: Jossey-Bass.

Kozlowski, S. W. J., \& Klein, K. J. (2000). A multilevel approach to theory and research in organizations: Contextual, temporal, and emergent processes. In K. J. Klein, \& S. J. W. Kozlowski (Eds.), Multilevel theory, research, and methods in organizations: Foundations, extensions, and new directions (pp. 3-90). San Francisco: Jossey-Bass.

LePine, J. A., Colquitt, J. A., \& Erez, A. (2000). Adaptability to changing task contexts: Effects of general cognitive ability, conscientiousness, and openness to experience. Personnel Psychology, 53, 563-593. 
Luthans, F. (2002a). The need for and meaning of positive organizational behavior. Journal of Organizational Behavior, 23, 695-706.

Luthans, F. (2002b). Positive organizational behavior: Developing and managing psychological strengths. Academy of Management Executive, 16, 57-72.

Luthans, F., Avey, J. B., \& Patera, J. L. (2007). An experimental analysis of a web-based training intervention to develop psychological capital. Academy of Management Learning and Education, In press.

Luthans, F., Avolio, B. J., Avey, J. B., \& Norman, S. M. (2007). Positive psychological capital: Measurement and relationship with performance and satisfaction. Personnel Psychology, 60, 541-572.

Mitchell, T. R. (1997). Matching motivational strategies with organizational contexts. In L. L. Cummings, \& B. M. Staw (Eds.), Research in organizational behavior (Vol. 19, pp. 57-149). Greenwich, CT: JAI Press.

Mullen, B., \& Copper, C. (1994). The relation between group cohesiveness and performance: An integration. Psychological Bulletin, 115, 210-227.

Mumford, T. V., Campion, M. A., \& Morgeson, F. P. (2006). Job and team design. In G. Salvendy (Ed.), Handbook of Human Factors and Ergonomics (3rd ed., pp. 428-457). Hoboken, NJ: John Wiley \& Sons.

Organ, D. W., \& Ryan, K. (1995). A meta-analytic review of attitudinal and dispositional predictors of organizational citizenship behavior. Personnel Psychology, 35, 1-62.

O’Driscoll, M. P., \& Beehr, T. A. (1994). Supervisor behaviors, role stressors and uncertainty as predictors of personal outcomes for subordinates. Journal of Organizational Behavior, 15, 141-155.

Peterson, C., \& Seligman, M. E. P. (2004). Character strengths and virtues: A handbook and classification. New York: Oxford University Press.

Porter, C. O. L. H., Hollenbeck, J. R., Ilgen, D. R., Ellis, A. P. J., West, B. J., \& Moon, H. (2003). Backing up behaviors in teams: The role of personality and legitimacy of need. Journal of Applied Psychology, 88, 391-403.

Richardson, G. E. (2002). The metatheory of resilience and resiliency. Journal of Clinical Psychology Special Issue: A Second Generation of Resilience Research, 58, 307-321.

Rousseau, D. M. (2000). Multilevel competencies and missing linkages. In K. J. Klein, \& S. W. J. Kozlowski (Eds.), Multilevel theory: Research and methods in organizations. San Francisco, CA: Jossey-Bass.

Seashore, S. E. (1954). Group cohesiveness in the industrial work group. Ann Arbor, MI: Institute for Social Research, University of Michigan.

Seligman, M. E. P., \& Csikszentmihalyi, M. (2000). Positive psychology. American Psychologist, 55, 5-14.

Seligman, M. E., \& Schulman, P. (1986). Explanatory style as a predictor of productivity and quitting among life insurance sales agents. Journal of Personality and Social Psychology, 50, 832-838.

Sheldon, K., \& King, L. (2001). Why positive psychology is necessary. American Psychologist, 56, 216-217.

Stajkovic, A., \& Luthans, F. (1998). Social cognitive theory and self efficacy: Going beyond traditional motivational and behavioral approaches. Organizational Dynamics, 26, 62-74.

Stewart, G. L. (2003). Toward an understanding of the multilevel role of personality in teams. In M. Barrick, \& A. M. Ryan (Eds.), Personality and work: Reconsidering the role of personality in organizations (pp. 60-82). San Francisco: Jossey-Bass.

Stout, R. J., Salas, E., \& Carson, R. (1994). Individual task proficiency and team process behavior: What's important for team functioning. Military Psychology, 6, 177-192.

Terrion, J. L., \& Ashforth, B. E. (2002). From 'I' to 'we': The role of putdown humor and identity in the development of a temporary group. Human Relations, 55, 55-58.

Tuckman, B. W. (1965). Developmental sequences in small groups. Psychological Bulletin, 63, 384-399.

Wagner, J. A. (1995). Studies of individualism-collectivism: Effects on cooperation in groups. Academy of Management Journal, 38, 152-172.

Watson, D., Clark, L. A., \& Tellegen, A. (1988). Development and validation of brief measures of positive and negative affect: The PANAS scales. Journal of Personality and Social Psychology, 54, 1063-1070. 